\title{
O ciberespaço e os mecanismos de busca: novas máquinas semióticas
}

\section{Silvana Monteiro}

Doutora em comunicação e semiótica.

E-mail: drumond@sercomtel.com.br

\section{Resumo}

Tal como as máquinas de busca, o ciberespaço se apresenta como uma nova máquina semiótica, desencadeando novos agenciamentos de escrita e organização do conhecimento. $O$ artigo discorre, brevemente, sobre os aspectos teóricos e práticos da organização do conhecimento no ciberespaço. Esse processo, realizado por meio da indexação e dos mecanismos de busca, comprova que não há uma sintaxe geral, bem como um sistema universal e dicotômico de classificação/catalogação do conhecimento, posto que o virtual opera a multiplicidade e a "desterritorialização" dos signos, tornando impossível um fechamento físico e semântico das obras.

\section{Palavras-chave}

Organização do conhecimento. Ciberespaço. Mecanismos de busca. Rizoma.

\section{The cyberspace and search engines: new semiotic machines}

\section{Abstract}

Like a search engine, the cyberspace is seen as new semiotic machine, which brings about new writing agencies and knowledge organization. In this sense, the new theoretical and practical aspects of the knowledge organization in cyberspace are discussed. This process, made by indexing services and search engines, confirms that there is no general syntax, neither any universal or dichotomy system of knowledge classification/cataloguing. This is because the virtual environment operates the multiplicity and the "deterritorialization" of signs, making impossible the physic and semantic closing of works.

\section{Keywords}

Knowledge organization. Cyberspace. Search engines. Rhizome.

\section{O CIBERESPAÇO}

Como um ser que (ainda) representa o mundo verbalmente, não poderia começar o artigo sem falar, mesmo que brevemente, da escrita. A escrita foi o primeiro sistema a tornar possível a máquina abstrata do "universal", ou seja, não há universal sem a escrita, sendo que esta (a escrita) configurou a possibilidade da universalidade, de modo que era (e ainda é) possível estender e fixar os discursos para além do tempo e do espaço em seus suportes físicos de registro (códex), podendo ser resgatados mediante condições de interpretação, condições essas inerentes à própria palavra, pelo poder simbólico de representação do significante, compartilhado por convenções e pactos sociais de inteligibilidade.

Portanto, tem-se na escrita o signo sedentário, permanente e fixo, ao qual é possível voltar e instaurar todas as práticas hermenêuticas e universais (calcadas no significado), elogiadas por muitos, criticadas por poucos, como os filósofos Deleuze e Guattari (1995, v. 1-2).

Nesse contexto, aprimorando o paradigma da escrita, a organização do conhecimento buscou no significado uma classe e um termo que valem como referentes ontológicos.

Assim, o sentido único da linguagem indicado pelo bom senso (primeiro elemento da doxa*), seja pela força da interpretação, é a afirmação de que em todas as coisas há um bom sentido determinável, ou uma "boa significação", e por extensão uma classe ou um significante certo adotado à organização do conhecimento. Ao mesmo tempo, o conhecimento é designado por identidades fixas do senso comum (segundo elemento da doxa), pelas quais o mundo é identificado e compreendido a partir de unidades estabilizadas do sentido, ou a homogeneidade dos objetos científicos que a etiqueta da biblioteca impõe como identidade fixa do conhecimento. Poderíamos ilustrar essa síntese da seguinte maneira:

\footnotetext{
* Os elementos da doxa em Platão são o bom senso e o senso comum, que Deleuze (1998), na "lógica do sentido", relacionou com o funcionamento da linguagem verbal escrita, mais especificamente com os aspectos ligados à interpretação, quer seja, com a instauração do significado.
} 


\section{identidades fixas (senso comum) do sentido único (bom senso) $=$ \\ $=$ referência fixa do conhecimento catalogado e classificado.}

O ciberespaço evidencia a ruptura com o sentido único e com as identidades fixas, ou seja, o bom senso e o senso comum, respectivamente, uma vez que o sentido é sempre um constructo, um acontecimento. Aqui, um acontecimento da ordem da ciência, da técnica, da ação, da cultura e do pensamento, de acordo com Lévy (2000a). Rompe, também, com a escrita linear, fixa e com a "ditadura da linha", no dizer de Bellei (2002).

Sendo o ciberespaço o espaço possível de criação de expressões culturais, ou seja, a cibercultura, de transações comerciais, econômicas e sociais, abordaremos o ciberespaço como um espaço semântico/semiótico, onde o signo se dá em várias semióticas, desterritorializado, nômade, em escrita espacializada e com a memória em constante modificação.

Alguns teóricos vislumbraram um tipo de escrita fragmentada, que só poderia ser visualizada, para a maioria, no ciberespaço, como a teoria da desconstrução (na escrita e a morte do autor) em Derrida, que antecipa modificações na escrita, como Barthes e as lexias de bricolagem textual (lexias semânticas, de ação de antítese, hermenêuticas e de referência cultural) ou mesmo Foucault entendendo o texto como uma rede formada de interconexões, tais como a conveniência, a emulação, a analogia e a simpatia (apud BARRETO, 2004)*.

Enfocando a tecnologia, encontram-se os decantados (e com razão) pelos artigos científicos, Vanivar Bush, com a idéia do Memex, um sistema de arquivo e recuperação configurado por várias linguagens e informações, e Ted Nelson, com os princípios de "textos paralelos" e o "docuverse", ambos precursores do conceito "hipertexto" e da noção de escrita (e biblioteca) em rede.

Na literatura, encontramos Landow (1995) com os princípios do hipertexto, como a intertextualidade, multivocalidade, descentralidade e rizoma - este último de Deleuze e Guattari (infracitados). Entretanto, os pressupostos que aqui utilizaremos são filosóficos, tais como "paradoxo do sentido", "virtual" e "rizoma" de Deleuze

\footnotetext{
* Barreto (2004), em seu artigo "As palavras voam, a escrita permanece: a aventura do hipertexto", fez um excelente trabalho ao resgatar as bases teórico-lingüísticas do hipertexto. Não nos estenderemos aqui na explicação de cada teoria citada, pois esse não é o objeto específico deste artigo.
}

e Guattari (1995, v. 1-2; 1998), pois explicam o "sentido" das linguagens em sua representação, instauração, utilização e organização, ou seja, a pragmática da linguagem.

Nesse contexto, o ciberespaço é uma máquina semiótica com os signos em constante fluxo, em permanente desterritorialização. Em primeiro lugar, é preciso retomar o conceito de máquina abstrata*. $\mathrm{O}$ mesmo não está ligado somente ao aspecto técnico, mas a máquinas cognitivas, afetivas, sociais, semióticas e também materiais, assim que, para Guattari (1992, p. 51), é preciso considerar que existe uma essência maquínica que irá se encarnar em uma máquina técnica, mas igualmente no meio social, cognitivo (ligado a essa máquina), pois

[...] os conjuntos sociais são também máquinas, o corpo é uma máquina, há máquinas científicas, teóricas, informacionais. A máquina abstrata atravessa todos esses componentes heterogeneamente [...], transversalmente.

As novas tecnologias (a propósito da nossa visão maquínica nos estudos sobre as formas simbólicas), antes de instaurar uma crise de representação, refletem o momento em que há o crescimento de complexidade na cognição, nas linguagens, na produção e organização do conhecimento.

Os agenciamentos maquínicos cognitivos decorrentes da semiótica da Internet que efetuam a máquina abstrata são outros e, para entendê-los, há de se abandonar uma visão verbalista e transcendental. São agenciamentos de linguagem que se relacionam no campo social e tornam a máquina abstrata concreta, produzindo mudanças significativas na forma de escrever, organizar e entender o mundo, a partir das formas simbólicas e da comunicação.

* O que denominam "máquina abstrata" constitui e conjuga todos os picos de desterritorialização do agenciamento. É uma nova teoria da expressão. O termo original foi empregado por Chomsky, criador da gramática generativa e transformacional, para explicar a raiz da linguagem, mas sempre uma abordagem rebatida sobre a própria linguagem. A novidade aqui consiste em resituar, na concepção maquínica, os agenciamentos de enunciação, que, nesta última, integrariam as substâncias de expressão além dos domínios da semiótica e da semiologia, como domínios extralingüísticos. Essa máquina propõe substituir os sistemas semiológicos e semióticos do estruturalismo por uma maquínica que engloba as problemáticas não apenas da expressão e do conteúdo, mas também as dos aspectos sociais, estéticos, científicos etc. Existe a modelização dessa máquina, com seus funtores ontológicos, que são expressão, conteúdo, território e desterritorialização (ver Guattari, 1992). 
O ciberespaço é uma máquina abstrata, onde se dá o pico de desterritorialização dos agenciamentos dos signos, a partir do virtual ou da virtualização e das conexões. Um agenciamento está tanto mais próximo da máquina abstrata, quanto mais abre e multiplica as conexões, as relações, pois o agenciamento pode ser entendido como conexão e a máquina abstrata como o acontecimento advindo dessas relações. Já o conceito de desterritorialização pode ser entendido como movimento, fluxo, aquilo que não se fixa em um território, que não perde a sua virtualidade. Filosoficamente, em Deleuze e Guattari (Mil Platôs, 5 v.), é o quarto elemento do diagrama (contra a estrutura) da linguagem, sendo o primeiro elemento a expressão, o segundo, o conteúdo, e o terceiro, o território.

Assim, o ciberespaço emerge como uma máquina abstrata, um espaço de inscrição virtual a partir da mídia digital e da hibridização das linguagens. Lévy (1996), seguindo Deleuze (por sua vez se referindo a Bergson*), escreveu sobre o virtual e seus desdobramentos filosóficos. A palavra virtual no sentido filosófico, que nos interessa, vem do latim medieval virtualis, derivação de virtus, designando força ou potência. $\bigcirc$ virtual existe em potência, e não em ato, por isso tem como pólo o atual, e não o real, como comumente associamos ao termo.

Assim, o virtual é potência em curso de atualização, e ambos pertencem ao real. Exemplificando o virtual, Lévy (1996) lança a situação da árvore que está virtualmente presente na semente. Então, o termo "virtual" não pode se opor ao real, mas ao atual, uma vez que a virtualidade e atualidade são apenas duas maneiras de ser diferentes. Nesse contexto, o virtual não substitui o real, mas antes multiplica as oportunidades para atualizá-lo.

Ainda de acordo com o autor, o virtual

[...] é como o complexo problemático, o nó de tendências ou de forças que acompanha uma situação, um acontecimento, um objeto ou uma entidade qualquer, e que chama um processo de resolução: a atualização (LÉVY, 1996, p.16).

O ciberespaço parece encarnar a força virtual, em curso de atualização, mas, ao mesmo tempo, sem perder a sua virtualidade, pois o virtual como realidade diz respeito ao modo de ser das "coisas" incorpóreas, portanto da ordem da memória e da produção simbólica, e no ciberespaço a mídia potencializa a reclamada virtualidade da língua por Deleuze e Guattari (em várias obras).

* Deleuze (1999).
O devir do virtual é de natureza paradoxal, de acordo com Deleuze (1998) em seu paradoxo do sentido (contra o bom senso e o senso comum, os elementos da doxa) em que a simultaneidade torna impossível uma identificação, colocando a ênfase ora em um, ora em outro aspecto, não sendo possível, portanto, calcar-se na determinação da significação ou da identidade fixa dos referentes ontológicos (das classificações biblioteconômicas), porque o paradoxo do sentido está em repartir-se em espaço aberto, em vez do espaço fechado das propriedades e classes, em que o bom senso reúne todos os sentidos.

Essa teoria do paradoxo do sentido, Deleuze (1998)* a fez baseando-se em Alice, da história de Lewis Carroll. O "País da Maravilhas" tem sempre uma dupla direção, como também ela é (Alice) aquela que sempre perde a identidade, a sua, a das coisas e a do mundo.

Dessa forma, não há descontextualização definitiva entre o ambiente de produção e de recepção do texto. É sempre possível contextualizá-lo, tanto do ponto de vista da escrita, quanto da leitura. A importância do paradoxo do sentido reside no fato de que, no ciberespaço, destrói o bom senso como sentido único, uma vez que é a indicação dos dois sentidos ao mesmo tempo, e destrói o senso comum como designação de identidades fixas.

O descolamento das formas simbólicas de seus suportes físicos faz com que seja possível visualizar a circulação do sentido, que vai e volta, onde o sentido é sempre um efeito

[...] não somente um efeito no sentido causal, mas um efeito no sentido de 'efeito óptico', 'efeito sonoro', ou melhor, efeito de superfície, efeito de posição, efeito de linguagem (DELEUZE, 1998, p. 73).

\footnotetext{
* Questão da identidade perdida: "Quem é você? Perguntou a Lagarta. Alice respondeu, meio encabulada: "eu... nem sei, Sir, neste exato momento ... pelo menos sei quem eu era quando me levantei esta manhã, mas acho que já passei por várias mudanças desde então." [...] "Receio não poder me explicar, respondeu Alice, porque não sou eu mesma, entende?" (CARROLL, 2002. Alice: Alice no país das maravilhas, p. 45). Questão das duas direções: Nessa história, Alice tem a capacidade de crescer e diminuir sucessivamente com a ingestão de um cogumelo, isto é, ir às duas direções, e quando se diz "ao mesmo tempo" quer dizer que ela não tomava apenas uma direção, como o fazemos nas interpretações e na fixação do significado, mas as duas. Essa questão é mais profunda em "Alice através do Espelho", onde Carroll brinca com a imagem especular invertida de qualquer objeto assimétrico. Quer dizer, em um espelho todos os objetos assimétricos (que não se sobrepõem em suas imagens especulares) ficam ao contrário. Assim a proposição "ir às duas direções ao mesmo tempo" ganha sua real potencialidade, com Alice caminhando para trás para chegar à frente, pois as direções frente e trás são invertidas quando se caminha em direção a um espelho, movendo a imagem oposta (CARROLL, 2002. Alice: Alice através do espelho).
} 
Ao reler a citação, o autor parece nos estar descrevendo o ambiente híbrido das linguagens multimídias no ciberespaço.

Se a organização do conhecimento possível para o códex é a hierarquia, as raízes, a árvore e a estrutura, no ciberespaço vem se configurando sob a forma em que se desenha o "rizoma". Segundo Deleuze e Guattari (1995, v.1), o rizoma pode ser resumido da seguinte maneira:

1) conexão: a possibilidade de conectá-lo em qualquer ponto do sistema, diferentemente da árvore ou raiz onde as conexões possíveis se dão hierarquicamente, por meio de um centro de significância;

2) heterogeneidade: os traços conectados não dizem respeito somente aos significantes, mas a regimes de signos muito diferentes formando semióticas múltiplas;

3) multiplicidade: princípio filosófico que se contrapõe ao pensamento dipolar e suas relações dicotômicas e hierárquicas. Para os autores, não é um múltiplo que se deriva do Uno e nem ao qual o Uno se acrescentaria $(n+1)$, mas o Uno é sempre subtraído dele (n-1). Como ele não possui estrutura, porque não advém do Uno-dois, ou seja, do pensamento dipolo, o múltiplo possui $n$ dimensões, com suas linhas de fuga e de desterritorialização;

4) a-significante: assim sendo, não existe então um sistema centrado de significância, o rizoma é a-centrado, não-hierárquico e não-significante, por isso mesmo não tem começo ou fim, mas sempre um meio pelo qual ele cresce e transborda, não precisando do "corte significante". Ao contrário de um livro, que possui seus pontos culminantes, o rizoma é feito de platôs, ou seja, uma região contínua de intensidades;

5) cartografia: o rizoma não é objeto de reprodução, nem externa como a árvore-mundo, nem interna, como a estrutura-árvore, porque o mesmo não tem centro, hierarquia e corte significante, então, suas ligações ilustram um mapa, e como tal possui várias entradas onde seu sentido dar-se-á por meio de cartografias;

6) decalcomania: na verdade é um antiprincípio, pois a decalcomania considera o livro como um decalque,

[...] decalque dele mesmo, decalque do livro precedente do mesmo autor, decalque de outros livros sejam quais forem, decalque interminável de conceitos e palavras bem situados, reprodução do mundo presente, passado ou por vir.
Nesse sentido a cartografia atua também contra os cortes significantes que levam à redundância do significante, à reprodução, à decalcomania (DELEUZE; GUATTARI, 1995, v. 1, p. 36).

\section{A ORGANIZAÇÃO DO CONHECIMENTO NO CIBERESPAÇO: ASPECTOS TEÓRICOS}

Eis a nossa síntese e propósito desta comunicação: relacionar o princípios do rizoma (que são os do hipertexto) com a organização do conhecimento no ciberespaço. Consubstanciando conceitos como "rizoma" e "indexação", que aparentemente se apresentam tão distantes, na verdade essa aproximação demonstra que os conceitos são nômades, passando de um território do saber ao outro, e demonstra também, de acordo com Deleuze e Guattari, que um conceito está privado de sentido enquanto não concorda com outros conceitos (1997).

A organização do conhecimento no ciberespaço, hoje, é possível a partir da indexação realizada pelas máquinas de busca, ou seja, mecanismos de busca e metabusca na Internet. Ao buscar os conceitos principais relacionados a essa indexação e que explicassem cientificamente esse processo, recorremos aos termos "rizoma" "virtual" e "paradoxo do sentido" e seus agenciamentos maquínicos.

Dessa maneira, os indexadores (mecanismos de busca) da Internet, como modelo de organização do conhecimento, detêm os mesmos atributos do rizoma, operando a multiplicidade do sentido existente na forma hipertextual (ou rizomática) à recuperação da informação e do conhecimento, não incorrendo no bom senso (sentido único) e senso comum (identidade fixa), ambos elementos da doxa, ou seja, no fechamento semântico (do significado/conteúdo) e físico (da materialidade/ forma) das obras e bibliotecas que deram origem à referência fixa do conhecimento.

Assim como na representação do conhecimento no ciberespaço, os mecanismos de busca, em geral, apresentam os princípios do rizoma de paradoxo do sentido, a saber:

1) conexão: a possibilidade de conectá-lo em qualquer ponto do sistema, diferentemente da árvore ou raiz onde as conexões possíveis se dão hierarquicamente, por meio de um centro de significância. Como o conhecimento está configurado no ciberespaço em forma rizomática, assim também os serviços de pesquisa comportam-se nos resultados retornados e, de pronto, tem-se acesso aos 
mesmos na íntegra. Escapa do fechamento físico das obras e do paradigma da materialidade e da noção de acervo ou armazenagem do conhecimento. Aqui as formas simbólicas encontram-se em fluxo, em estado contínuo e contíguo no mesmo espaço semântico/semiótico. Tudo pode entrar em relação com tudo: o continuum semiótico;

2) heterogeneidade: os traços conectados não dizem respeito somente aos significantes (palavras), mas a regimes de signos muito diferentes. $O$ resultado de busca, ou a própria busca, pode aparecer sob várias linguagens, imagens, textos, músicas, ilustrando a descentralização do verbalismo na organização do conhecimento no ciberespaço, como, por exemplo, o KaZaA, que busca e compartilha multimídia, ou mesmo o Google, que busca o conhecimento diretamente por imagens (ícones). Vários regimes de signos e mídias não só à representação, mas também à organização do conhecimento;

3) multiplicidade: a multiplicidade é, sobretudo em seu sentido filosófico, a produção do conhecimento (e da escrita) que favorece uma topologia das multiplicidades, em forma de "diagrama", e não uma raiz ou estrutura, sendo, portanto, contra o pensamento dipolo. A multiplicidade é a própria realização do rizoma: vários modos de pensar, escrever, várias linguagens, formas de indexação e recuperação do conhecimento. No ciberespaço, não há centro de significância estruturado, hierarquizado, linear, ou instrumentos de organização do conhecimento que reproduzem o modelo de significância, sentido único e referência fixa. A multiplicidade e as várias possibilidades de tratamento da informação no ciberespaço ilustram que não há uma maneira correta de organização do conhecimento que deva ser empregada e reproduzida pelos outros sistemas para tentar atingir a "universalidade", ou seja, não há um modelo geral de indexação, muito menos um modelo dicotômico de organização do conhecimento (forma e conteúdo);

4) a-significante: assim sendo, não existe então um sistema centrado de significância, o rizoma é a-centrado, não-hierárquico e não-significante. Quando se utiliza CASA, CASAS, HOUSE... na recuperação da informação, não há um centro de significado, ou significância, expresso em um só termo autorizado utilizado à busca. Todos os termos são possíveis. A ruptura a-significante não opera mais, do menos diferenciado, ao mais diferenciado, dos gêneros às espécies, do geral para o específico (lógica formal de organização do conhecimento), como nas classificações hierárquicas, mas por meio de linhas de fuga, pelo meio, aqui e ali, o léxico comporta-se assim. Os indexadores não buscam apenas pelos substantivos (substância) que refletem o assunto principal: toda e qualquer palavra de enunciação, ou seja, não há uma sintaxe geral;

5) cartografias: o rizoma não tem centro, hierarquia e corte significante, então suas ligações ilustram um mapa, e como tal possui várias entradas onde seu sentido darse-á por meio de cartografias. "Mover", essa é a função da desterritorialização, sair e entrar, sem começo ou fim, tudo parece ser pego pelo "meio". Isso posto, os serviços de busca ou pesquisa devem ser considerados como ferramentas de cartografia a serviço do leitor ou usuário que fará, por si só, suas ligações de contexto, seu próprio mapa cognitivo, ou seja, não há um caminho certo, nem linear à busca do conhecimento;

6) decalcomania: o rizoma não é objeto de reprodução interna como a estrutura-árvore, porque o mesmo não tem centro, hierarquia e corte significante, ou seja, a estrutura. A arquitetura da cartografia vai contra a estrutura do texto e dos sistemas de indexação tradicionais decalcados.

Para Deleuze (1998), o paradoxo do sentido na linguagem é exemplificado de duas maneiras. Primeiro, pelo duplo sentido ou direção (contrariando o bom senso), já exemplificado pela Alice, e por sua vez explica o ciberespaço. No meio digital, esse paradoxo pode ser sentido entre o puxar e avançar da escrita/leitura, bem como não há o sentido único, o significado certo a ser instaurado ou utilizado na organização do conhecimento.

No segundo caso do paradoxo do sentido, diz respeito à identidade perdida (contra o senso comum), a impossibilidade de se atribuir a identidade única à Alice, assim como no ciberespaço não há referências (identidades) fixas do conhecimento, em que se possa atribuir uma estabilidade dos referentes ontológicos, tal como nas classes destinadas a esse objetivo, na pragmática da escrita e da organização do conhecimento.

O meio digital veio para demonstrar a tese que Deleuze (1998) já havia defendido somente no âmbito da linguagem. Os agenciamentos por ele identificados na instauração do sentido, na linguagem verbal escrita, só são sentidos agora, com a "desterritorialização" dos textos no ciberespaço, por isso mesmo o "virtual" é o principal atributo do ciberespaço, porque ele demonstra e faz possível identificar a escritura rizomática no hipertexto, e o paradoxo do sentido da linguagem, que aqui é do meio (mídia) também, e todos esses elementos estão presentes na organização virtual do conhecimento. 
A organização clássica do conhecimento usa o esquema da Árvore de Porfírio, que tem como modelo e definição as dicotomias sucessivas, ordenando as idéias segundo sua compreensão crescente e extensão decrescente, relacionando de forma indistinta a realidade espiritual e a realidade natural. Assim é o agenciamento da Árvore de Porfírio e da escrita: "[...] a subsunção da realidade natural (mundo) à realidade espiritual (livro)" (FRAGOSO, 1997, p. 88).

Em suma, o paradoxo do sentido, na organização do conhecimento no ciberespaço, torna instáveis os principais atributos da doxa. É uma nova maneira de produzir sentido e de buscar assuntos, mais livre, mais incerta.

O ciberespaço está misturando as noções de unidade, de identidade e de localização, atributos relacionados à identidade única, à determinação de unidades estabilizadas do sentido por meio do senso comum. Todas essas implicações atingem diretamente a questão da identidade dos assuntos e da localização fixa dos volumes ordenados em acervos fisicamente codificados, que no ciberespaço não existem. Lévy (1996, p.25) afirma que as coisas só têm limites claros no real, pois

[...] a virtualização, passagem à problemática [caso do ciberespaço], deslocamento do ser para a questão, é algo que necessariamente põe em causa a identidade clássica, pensamento apoiado em definições, determinações, exclusões, inclusões [...].

\section{A ORGANIZAÇÃO DO CONHECIMENTO NO CIBERESPAÇO: ASPECTOS PRÁTICOS. TUDO NO MESMO LUGAR, EM TODO LUGAR}

Como já vimos, o léxico do ciberespaço, especificamente na organização do conhecimento, não tem um termo, classe ou mesmo um significante adotado como "certo" ou como sentido único à organização e recuperação do conhecimento, ou seja, UMA SINTAXE GERAL; por isso mesmo, o significado (seja uma classe ou um descritor), como expressão única ou primordial, não desempenha papel principal na determinação da significação.

A grande corrida dos programadores, a de maior investimento atualmente, está em buscar um software que consiga interpretar o "sentido", conforme já anunciado pelo Consórcio W3, em que o criador da Web, Tim Berners-Lee, faz parte da chamada "rede semântica". Embora não exista ainda a Web semântica, seria bom salientar que a proposta de seus pesquisadores não está em "fechar" o sentido em um significado, mas ter tecnologia capaz de atribuir semântica à busca do conhecimento. $O$ sentido seria contextualizado de acordo com o usuário em tela, e para tanto as ontologias funcionariam como linguagem de representação do conhecimento (leia-se representação, e não organização), estabelecendo as relações e inferências necessárias entre o usuário e as camadas semióticas. Assim sendo, precisamos tomar cuidando para não confundir as ontologias com os tesaurus.

Com relação à Web atual, podemos citar o A9, da Amazon (www.amazon.com), que consiste em um agente inteligente que faz associações entre as compras dos leitores e indica outras referências a partir do cruzamento dessas informações. Por exemplo: um leitor A, que comprou um livro $\mathrm{X}$, e outro comprador B, que comprou o mesmo livro X, o A9 estabelece algum ponto de intersecção de interesse entre $\mathrm{A}$ e $\mathrm{B}$, e assim toda vez que o leitor A comprar outro título, isso será indicado ao leitor B (e vice-versa), posto que podem ter alguma afinidade temática.

Enfim, são recursos, ferramentas e possibilidades que demonstram a multiplicidade no processo de busca. Não se faz a busca só de uma maneira, um sistema adotado, de uma forma certa, a propósito da obra acabada. Faz-se a busca de uma maneira, e outra, e um recurso leva ao outro e outro mais. Uma palavra, seus sinônimos, seus congêneres em outros idiomas, por sua imagem, ou por grupos de discussão, ou ainda por categorias de multimídias.

Confirmando essa idéia, podemos encontrar a multiplicidade nos buscadores citados a seguir demonstrando que NÃO HÁ UM MODELO GERAL, a saber:

A9: procura palavras em mais de 120 mil livros e guarda histórico das buscas: < www.a9.com $>$;

Eurekster: organiza os resultados de acordo com indicações de amigos: < www.eurekster.com>;

Feedster: procura somente em blogs e ordena os resultados por assunto ou data: < www.feedster.com $>$;

Scirus: uma ferramenta de pesquisa especializada em publicações científicas: < $\underline{w w w . s c i r u s . c o m}>$;

Teoma: percebe a Web como se fosse uma reunião de comunidades discutindo assuntos diferentes e procura, em cada uma delas, a página com mais autoridade: $<$ www.teoma.com $>$; 
Vivíssimo: tenta entender o significado das páginas e reuni-las por assunto. Depois, organiza os temas em hierarquias também chamadas "taxonomias"; $<$ www.vivissimo.com $>$ (KENSKI, 2004, p. 62).

Tudo no mesmo lugar se refere às ambições do Google, que, além de possuir e-mail gratuito com 1 gygabyte de espaço (gmail.google.com), busca de produtos (www.froogle.com), uma ferramenta de blogs (www.blogger.com), listas de discussão (groupsbeta.google.com) e um buscador de notícias (news.google.com), estuda a possibilidade de o usuário guardar todos seus programas e arquivos dentro do próprio Google, ou seja, "tudo no mesmo lugar" para que o acesso se dê "em qualquer lugar", seja de um celular, de outro PC, enfim, desde que essas informações estejam na Web. E não é só isso. Pretende desenvolver tecnologias a partir do perfil do usuário, que usa várias das suas ferramentas para aperfeiçoar a busca de informações, com base nas associações ou relações semânticas desse usuário.

O mais novo projeto do Google é o "Google print", dando início ao sonho dos bibliotecários e escritores, como Borges em seu conto "A biblioteca de Babel" e Ted Nelson com o docuverse, ou seja, uma biblioteca global eletrônica de documentos interconectados. O projeto prevê um acordo entre o Google e as maiores bibliotecas do mundo - a pública de Nova York, a das universidades norte-americanas de Stanford, Harvard, de Michigan e da Universidade de Oxford (LIMA, 2004). Trata-se da digitalização de mais de 16 milhões de livros, permitindo que grande parte deles possa ser consultada pela Internet.

Dessa forma, o mecanismo de busca atuaria diretamente na biblioteca, ou seja, no próprio conhecimento de duas maneiras: se a obra recuperada for de domínio público, o leitor poderá imprimi-la; se estiver protegida por direitos autorais, o Google o encaminhará a uma livraria para que possa adquiri-la, caso deseje assim.

A indexação na Internet realizada pelas máquinas de busca, como modelo possível de organização do conhecimento, suplantando as práticas biblioteconômicas e dicotômicas tradicionais, como a catalogação (fechamento físico ou forma) e a classificação (fechamento semântico ou conteúdo), é uma tarefa gigantesca, posto que essa organização é "relativa”, e não sugerimos, em momento algum, que seja absoluta. Entretanto, temos sido privilegiados por novidades, serviços que se aperfeiçoam, flexibilizam-se, mediante as nossas necessidades de conhecimento e informação, mecanismos de busca poderosos e flexíveis, na especificação de argumentos de pesquisa que permitem realizar buscas com bom nível de controle.

\section{SOBRE O TEMPO E O ESPAÇO DO CONHECI- MENTO NO CIBERESPAÇO: CONCLUSÃO}

Cabe ressaltar como o tempo*, no pólo do espírito e da cognição, muda de acordo com as tecnologias. $\bigcirc$ tempo da escrita era um tempo linear, marcado pela história, pelos registros oficiais de conhecimento e pelos calendários. A escrita temporal guardava o tempoduração, o tempo-permanência do signo em seu espaço material de inscrição. Havia certo ritmo entre os acontecimentos e seus registros nos suportes de papel, a leitura e a interpretação. Havia o tempo de os bibliotecários aplicarem suas técnicas, elaborarem seus catálogos e índices. Acontece que esse tempo acelerouse, tornando-se em tempo real, de mudanças, de memória social em constante transformação.

Se considerarmos que um mecanismo de busca como o Google possui mais de 5 bilhões de web-pages, mais de 400 milhões de imagens indexadas, que traz um resultado, em média, em cinco segundos, em que uma pesquisa manual do material arquivado no Google levaria 5.707 anos (impossível!), que a cada segundo 3 mil pesquisas são feitas em 97 idiomas (quase 260 milhões em um dia), chegamos à conclusão de que o tempo no ciberespaço é real, e esse tipo de memória está mais relacionado ao espaço do que ao tempo, ao contrário das unidades impressas (CARELLI, 2002, p.98; GOOGLE, 2004; RYDLEWSKI, 2004, p. 148).

Essa é a dinâmica da distribuição das formas simbólicas no ciberespaço, e a busca contextual nesse espaço só pode ser feita por sistemas de navegação que compreendam e atualizem essa dinâmica. Parece que a aceleração acompanha, ou mesmo marca o desenvolvimento das tecnologias e do signo, e assim deverá caminhar a nossa cognição, de tal modo a compreender e apreender o conhecimento que é desterritorializante, marcado por uma escritura em movimento e espacial, sem a estabilidade das estruturas textuais, dos cânones lingüísticos e sem a referência fixa.

\footnotetext{
* Assistindo a uma apresentação de música e dança da Renascença (sécs. XV e XVI), percebemos a relação do tempo com as matérias de expressão ou linguagens, enfim, com a cognição, em que o tempo lento de marcação de ritmo da música refletia uma época que não havia sido atingida pela aceleração dos processos produtivos e pelas tecnologias da comunicação. Isso faz lembrar de uma frase de Guattari, que diz, "[...] o tempo discursivo é batido pelos relógios sociais." (GUATTARI, 1992, Caosmose, p. 131).
} 


\section{Silvana Monteiro}

Nesse sentido, Costa (2000, p. 191) chama a atenção ao dizer que [...] as mudanças tecnológicas não pedem uma adaptação das pessoas, mas sim, uma coevolução do coletivo como um todo [...] ", sobretudo em eventos em que o conhecimento está inserido (grifo do autor).

Todo sistema simbólico leva à instauração de algum sentido, de acordo com Lévy (2000b), e a passagem das culturas identitárias clássicas para uma outra, configurada pelas mídias digitais, leva à crise de sentido (leia-se, de sentido único), sendo que o ciberespaço é uma nova maneira de produzir sentido, mais livre, mais aberta. Assim serão também a organização e a recuperação do conhecimento, visto que fazem parte desse sistema simbólico.

Artigo submetido em 21/04/2005 e aceito em 10/07/2006.

\section{REFERÊNCIAS}

BARRETO, Aldo de Albuquerque. As palavras voam, a escrita permanece: a aventura do hipertexto. Datagramazero: Revista de Ciência da Informação, v. 5, n. 5, p. 1-13, out. 2004.

BELLEI, Sérgio Luiz Prado. O livro, a literatura e o computador. São Paulo: EDUC; Florianópolis: UFSC, 2002.

CARELLI, Gabriela. Eles buscaram e acharam: certeiro e veloz, o Google torna-se o site de busca mais bem-sucedido da Internet. Veja, São Paulo, ano 35, n. 16, p. 98, abr. 2002.

CARROLL, Lewis. Alice: aventuras de Alice no país das maravilhas \& através do espelho. Rio de Janeiro: Zahar, 2002.
COSTA, Rogério da. Um sistema de gestão de conhecimentos: filosofia, tecnologia e organizações. In: PELLANDA, Nize M. Campos; PELlANDA, Eduardo Campos (Org.). Ciberespaço: um hipertexto com Pierre Lévy. Porto Alegre: Artes e Ofícios, 2000. p. 187-195.

DELEUZE, Gilles. Bergsonismo. São Paulo: Ed. 34, 1999. - Lógica do sentido. São Paulo: Perspectiva, 1998. .. O que é a filosofia?. São Paulo: Ed. 34, 1997. ; GUATTARI, Félix. Mil platôs: capitalismo e esquizofrenia. São Paulo: Ed. 34, 1995. v. 1-2.

FRAGOSO, Emanuel Ângelo da Rocha. Deleuze e Platão: um banquete. In: VASCONCELLOS, Jorge; FRAGOSO, Emanuel Ângelo da Rocha. Gilles Deleuze: imagens de um filósofo da imanência. Londrina: Ed. UEL, 1997. p. 85-97.

GOOGLE. Disponível em: <www.google.com.br >. Acesso em: 12 set. 2005.

GUATTARI, Félix. Caosmose: um novo paradigma estético. São Paulo: Ed. 34, 1992.

KENSKI, Rafael. O mundo Google: ele mudou a internet e a nossa vida. Superinteressante, São Paulo, p. 55-63, jun. 2004.

LANDOW, George. Hipertexto: la convergência da la teoría crítica contemporánea y la tecnologia. Buenos Aires: Paidós, 1995.

LÉVY, Pierre. Cibercultura. São Paulo: Ed. 34, 2000a.

A Internet e a crise de sentido. In: PELLANDA, Nize M. Campos; PELlANDA, Eduardo Campos (Org.). Ciberespaço: um hipertexto com Pierre Lévy. Porto Alegre: Artes e Ofícios, $2000 \mathrm{~b}$. p. 21-25.

. O que é o virtual?. São Paulo: Ed. 34, 1996.

LIMA, João Gabriel de. Isso sim é revolução. Veja, São Paulo, ano 37, n. 51, p. 70-72, dez. 2004.

RYDLEWSKI, Carlos. Os bilhões do Google. Veja, São Paulo, ano 37, n. 33, p. 148-200. 